\title{
Discoloration Effects of High-Dose $\gamma$-Irradiation and Long-Term Thermal Aging of (U)HMW-PE
}

\author{
Anja Kömmling, ${ }^{1}$ Emmanouil Chatzigiannakis, ${ }^{1}$ Jörg Beckmann, ${ }^{1}$ \\ Volker Wachtendorf, ${ }^{1}$ Kerstin von der Ehe, ${ }^{1}$ Ulrike Braun, ${ }^{1}$ Matthias Jaunich, \\ Ulrich Schade, ${ }^{2}$ and Dietmar Wolff ${ }^{1}$
}

${ }^{1}$ Bundesanstalt für Materialforschung und -prüfung (BAM), 12200 Berlin, Germany
${ }^{2}$ Helmholtz-Zentrum Berlin für Materialien und Energie (HZB), 12489 Berlin, Germany

Correspondence should be addressed to Matthias Jaunich; matthias.jaunich@bam.de

Received 21 February 2017; Revised 20 June 2017; Accepted 5 July 2017; Published 6 September 2017

Academic Editor: Robert A. Shanks

Copyright (C) 2017 Anja Kömmling et al. This is an open access article distributed under the Creative Commons Attribution License, which permits unrestricted use, distribution, and reproduction in any medium, provided the original work is properly cited.

Two polyethylene types with ultra-high (UHMW-PE) and high molecular weight (HMW-PE) used as neutron radiation shielding materials in casks for radioactive waste were irradiated with doses up to $600 \mathrm{kGy}$ using a ${ }^{60} \mathrm{Co}$ gamma source. Subsequently, thermal aging at $125^{\circ} \mathrm{C}$ was applied for up to one year. Degradation effects in the materials were characterized using colorimetry, UV-Vis spectroscopy, IR spectroscopy, and DSC. Both materials exhibited a yellowing upon irradiation. The discoloration of UHMW-PE disappeared again after thermal aging. Therefore, the yellowing is assumed to originate from annealable color centers in the form of free radicals that are trapped in the crystalline regions of the polymer and recombine at elevated temperatures. For the antioxidantcontaining HMW-PE, yellowing was observed after both irradiation and thermal aging. The color change was correlated mainly to decomposition products of the antioxidant in addition to trapped radicals as in UHMW-PE. Additionally, black spots appeared after thermal aging of HMW-PE.

\section{Introduction}

Polyethylenes with high molecular weight (HMW-PE) or ultra-high molecular weight (UHMW-PE) have special properties such as good impact strength, abrasion resistance, and chemical stability [1]. Because of their high hydrogen content, they are also used as neutron radiation shielding material in casks for transport and/or storage of radioactive material $[2,3]$. In this application, the materials are exposed to high gamma radiation doses at elevated temperatures over long time periods.

To investigate the long-term material behavior relevant for this application, two different (U)HMW-PE materials were subjected to gamma irradiation and elevated temperature with doses and temperature comparable to those experienced during service. Property changes of these materials resulting from irradiation were already examined in [3-5] and could be attributed as well to chain scission reactions as cross-linking of the material. Chain scission became evident via the increased melting temperature and higher degree of crystallinity of the irradiated materials and cross-linking via the high increase in gel content and formation of a rubbery plateau.

The strong discoloration that was observed after irradiation changed again when subsequent thermal aging was applied. Investigating the development of discoloration in these materials and their origins as discussed in this paper can help to elucidate the physical-chemical degradation mechanisms acting in these materials when irradiation and thermal loads are applied. Furthermore, the molecular changes of the samples were analyzed and the materials were compared with regard to their degradation effects.

Irradiation and exposure to oxygen (either during irradiation or afterwards) lead to oxidation of the PE materials. The oxidation mechanisms of (U)HMW-PE have been discussed in detail previously [6-11]. The first step of oxidation is the formation of alkyl macroradicals which react with the oxygen dissolved in the polymer, forming peroxy radicals. If these 
peroxy radicals abstract hydrogen from another polymer chain (thus creating another alkyl radical), they become hydroperoxides. Under the influence of temperature, they decompose into carbonyls and other radical species such as hydroxyl radicals as well as alkoxy and alkyl macroradicals. Further oxidation species include carboxylic acids and alcohols as well as unsaturated species. The mentioned reaction products, which are formed both by thermooxidation and by postirradiation oxidation [7], can lead to discoloration of the material (see below). Furthermore, the oxidation rate depends, besides termination reactions and cross-linking, on oxygen availability and radical mobility [8], both of which are lower in the crystalline regions of the polymer. This is related to the degradation of amorphous phase and the resulting relative increasing content of crystalline phase or/and the reduction of molecular weight and the possible postcrystallization in the material. This has to be taken into account when analyzing bulk properties. Colorimetry and $\mathrm{UV}$-Vis spectroscopy were applied to characterize the color changes in detail. Changes in color after irradiation have been attributed to the formation of annealable or permanent color centers [12]. Annealable color centers are correlated to macroradicals (e.g., alkyl and allyl) that are trapped in rigid (glassy or crystalline) polymer matrices. At elevated temperatures, when the molecules have a higher mobility, the radicals can recombine or oxidize, thus annihilating the color center. On the other hand, permanent color centers are correlated to the formation of stable chemical species [13]. DSC measurements were performed for detecting changes of crystallinity related to the formation of annealable color centers. Furthermore, Fourier-transform infrared (FTIR) spectroscopy was carried out for investigating the formation of chemical species that contribute to discoloration.

In 2016 preliminary results were presented as a poster contribution to the Ionizing Radiation and Polymers Conference (IRaP) 2016 in Gience, France. Based on these results, additional investigations allowed for the in-depth discussion of color changes by irradiation and annealing presented in this paper.

\section{Experimental}

2.1. Materials. The analyzed linear UHMW-PE material is a GUR 4120 from Ticona (Celanese) containing a corrosion stabilizer. However, in earlier investigations [3], the UHMW$\mathrm{PE}$ exhibited no measurable oxidation induction time (OIT), so that the contained corrosion stabilizer apparently has no effect on the oxidation of the material. According to the manufacturer, the UHMW-PE has a molecular weight of about 5 million $\mathrm{g} / \mathrm{mol}$, which is more than ten times that of HMW-PEs.

The HMW-PE used in this study is a high-density Lupolen $5261 \mathrm{Z}$ from Lyondell Basell and contains the sterically hindered primary phenolic antioxidant Irganox 1076 according to the material data sheet.

The polymers were processed by compression molding into blocks that were cut into pieces of about $40 \mathrm{~mm} \times 80 \mathrm{~mm}$ $\times 200 \mathrm{~mm}$.
2.2. Irradiation and Thermal Aging. The samples were irradiated under air at ambient conditions with a ${ }^{60}$ Co gamma source by Synergy Health Radeberg GmbH, Germany, with an average dose rate of approximately $3 \mathrm{kGy} / \mathrm{h}$. The effected absorbed doses of 50,100,200, 400, and $600 \mathrm{kGy}$ were confirmed using a dosimeter. The absorbed dose is assumed to be homogeneous over the material thickness $(4 \mathrm{~cm})$ as the appropriate half value layer for PE is much larger (about $12 \mathrm{~cm}$ [14]). Furthermore, the samples were moved in a square around the gamma source, so that the radiation was applied from all sides, promoting a homogeneous dose distribution in the samples. Even though the irradiated blocks are comparatively thick, homogeneous oxidation after irradiation is assumed due to postirradiation oxidation; that is, there was enough time (several weeks between irradiation and examination) for the oxygen to diffuse into the sample and react with available radicals. Afterwards, irradiated as well as untreated blocks were thermally aged in an oven at $125^{\circ} \mathrm{C}$ for periods of 31 days, 183 days, and 366 days.

2.3. Characterization. All samples for the measurements were prepared from the interior part of the treated blocks, as the bulk properties and not the surface properties are relevant for the application as neutron shielding material. The blocks were cut into slices of $4 \mathrm{~mm}$ thickness, thus decreasing the diffusion path and accelerating postirradiation oxidation [15] of reactive species formed during irradiation in the bulk.

The colorimetry measurements were performed in reflection mode using a Minolta Spectrophotometer CM-2600d with a wavelength range of $360 \mathrm{~nm}$ to $740 \mathrm{~nm}, \mathrm{~d} / 8$ (diffuse illumination, $8^{\circ}$ viewing), $10^{\circ}$ observer, observation mask diameter $6 \mathrm{~mm}$. UHMW-PE and HMW-PE samples with a size of $200 \mathrm{~mm} \times 80 \mathrm{~mm} \times 4 \mathrm{~mm}$ were tested. In the case of UHMW-PE samples, measurements were conducted at three different points of the longer axis, all equally distant from each other. All samples were positioned over a black substrate to ensure a defined reference background and to avoid reflections from a light background. Calibration (zero and white standard) was done every 30 measurements. In the case of HMW-PE which exhibited black spots after thermal aging (cf. Figure 8), measurements were performed only in regions without black spots. The number of measurements varied from 3 to 5 until a standard deviation lower than $1 \%$ was obtained. The measured spectral reflectance data were transformed into the CIE- $L^{*} a^{*} b^{*}$ color coordinate system (according to EN ISO 11664-4), where $L^{*}$ is a measure of the lightness and $a^{*}$ indicates the position on the redgreen-axis and $b^{*}$ the one on the blue-yellow axis [16]. The yellowness index (YI) was used to quantify the total color change of a material. It takes into account changes in all $L^{*} a^{*} b^{*}$ coordinates and the contribution of each coordinate to the development of yellow color. It is calculated according to [17]

$$
\mathrm{YI}=100\left(\frac{0.72 a^{*}+1.79 b^{*}}{L^{*}}\right)
$$

The UV-Vis measurements were conducted on the same samples using a Varian Cary 300 UV-Vis Spectrometer and 
a LabSphere DRA-30I integrating sphere in double beam transmission mode. The use of an integrating sphere was necessary as the sample thickness of $4 \mathrm{~mm}$ and the high degree of crystallinity causes considerable stray light. The thickness of the samples also causes high UV absorption. In order to extend the effective detection limit, the measurements were carried out using an attenuated reference beam. The baseline was corrected for $100 \%$ transmission. All UV-Vis measurements were performed in the range of $220-850 \mathrm{~nm}$. The scan rate was adjusted to a constant signal/noise ratio of 1000:1 with a timeout of $2 \mathrm{~s}$. In the case of HMW-PE samples, measurements were conducted on regions containing no black spots, as they exhibited absorption beyond the detection limit of the system.

The Fourier-transform infrared (FTIR) spectroscopy was conducted in vacuum with a Bruker Vertex $80 / v$ spectrometer which is attached to the infrared beamline at the electron storage ring BESSY II [18]. A MCT detector and a $\mathrm{KBr}$ beam splitter were used to cover the mid infrared wavelength range. The measurements on $4 \mathrm{~mm}$ thick samples were performed in transmission mode employing the empty beam path of the spectrometer as a reference. Spectra of $2 \mathrm{~cm}^{-1}$ resolution were acquired from 256 scans. No normalization procedure was applied; however, the spectra were shifted on the $y$-axis until the baselines overlapped at the bottom of the respective characteristic peak.

Differential scanning calorimetry (DSC) was conducted using a Netzsch DSC 204 F1 Phoenix on samples with a mass of $5-10 \mathrm{mg}$ with two heating runs (heating rate $10 \mathrm{~K} / \mathrm{min}$ ) in a temperature range of $-50^{\circ} \mathrm{C}$ to $200^{\circ} \mathrm{C}$. The degree of crystallinity was evaluated by dividing the melting peak area (corresponding to the specific melting enthalpy) between $50^{\circ} \mathrm{C}$ and $160^{\circ} \mathrm{C}$ in the second heating run by the reference value for completely crystalline PE (293 J/g) [19].

\section{Results}

\section{1. $U H M W-P E$}

3.1.1. Colorimetry. Figure 1 shows the yellowness index (YI) of UHMW-PE that was first irradiated with different doses and then thermally aged at $125^{\circ} \mathrm{C}$. As can be seen from the data points at zero aging time, pure gamma irradiation resulted in a pronounced increase of YI. This has been attributed to allyl or alkyl radicals which were formed by chain scission reactions as a result of irradiation and which act as annealable color centers, as discussed, for example, by Martínez-Morlanes et al. [13]. When these macroradicals are formed in the crystalline regions of the polymer, they are trapped there and are relatively stable, according to [20,21]. The very high molecular weight of UHMW-PE chains further enhances the stability of these macroradicals, as the low mobility of the chains hinders propagation reactions [22]. On the other hand, pure thermal aging (graph for $0 \mathrm{kGy}$ ) only led to a slight increase of YI. Furthermore, the intense discoloration after irradiation was revoked by thermal aging which can be explained by the recombination or oxidation of the trapped radicals enabled by higher mobility of the

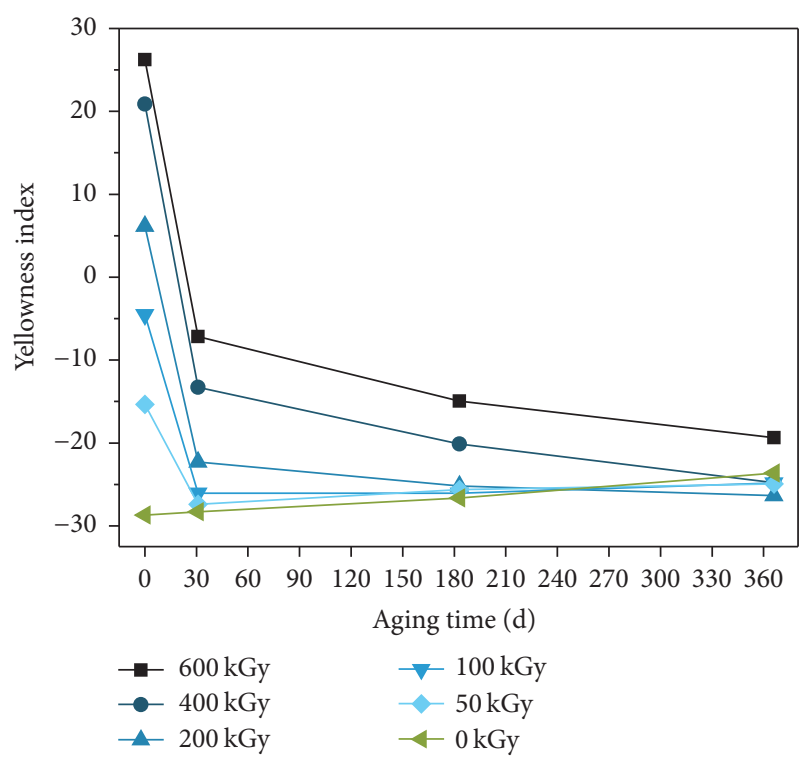

FIGURE 1: Yellowness index of UHMW-PE after irradiation and subsequent thermal aging at $125^{\circ} \mathrm{C}$.

molecules at the temperature of $125^{\circ} \mathrm{C}$ used for thermal aging [20].

3.1.2. UV-Vis. UV-Vis measurements were conducted to gain more detailed information on the absorption changes that gave rise to the discoloration in the Vis range and which might show additional features in the UV range. Figure 2 shows the UV-Vis absorbance spectra of the samples. The observed effects of irradiation that are also described in literature are (i) a gradual increase in the total absorbance of the material, indicating the formation of absorbing species such as unsaturations, hydroxyl, or carbonyl groups [23], (ii) shifting of the curves to higher wavelengths as a result of the formation of conjugated sequences with increasing length [20,24], and (iii) formation of a peak around $355 \mathrm{~nm}$ which is probably related to the free radicals that form the color centers. On the other hand, pure thermal aging (Figure 3) only led to a slight red shift, probably because of oxidation species mentioned above (i). When the irradiated polymer was subjected to thermal aging, the absorbance spectra gradually returned almost to the initial curve and the red-shifting was revoked (Figure 4), confirming that the observed color centers were annealable and not permanent.

3.1.3. DSC. Figure 5 shows the DSC curves of the first heating run both before and after irradiation, corresponding to the material behavior before the application of thermal loads. Besides a shift of the melting peak to higher temperatures after irradiation, it can be seen that, at the aging temperature of $125^{\circ} \mathrm{C}$ (marked by the dotted line) that is applied afterwards, the smallest crystals start to melt in both the untreated and the irradiated material. Thus, molecular rearrangements and migration of trapped radicals from the crystalline regions are possible at this temperature, which can 


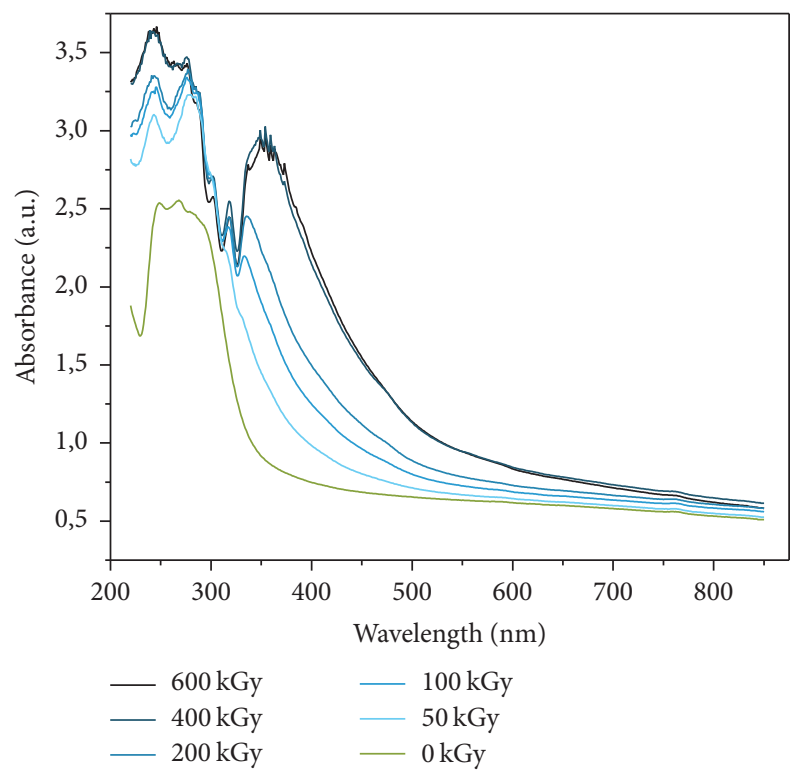

FIGURE 2: UV-Vis absorption spectra of UHMW-PE after irradiation with different doses.

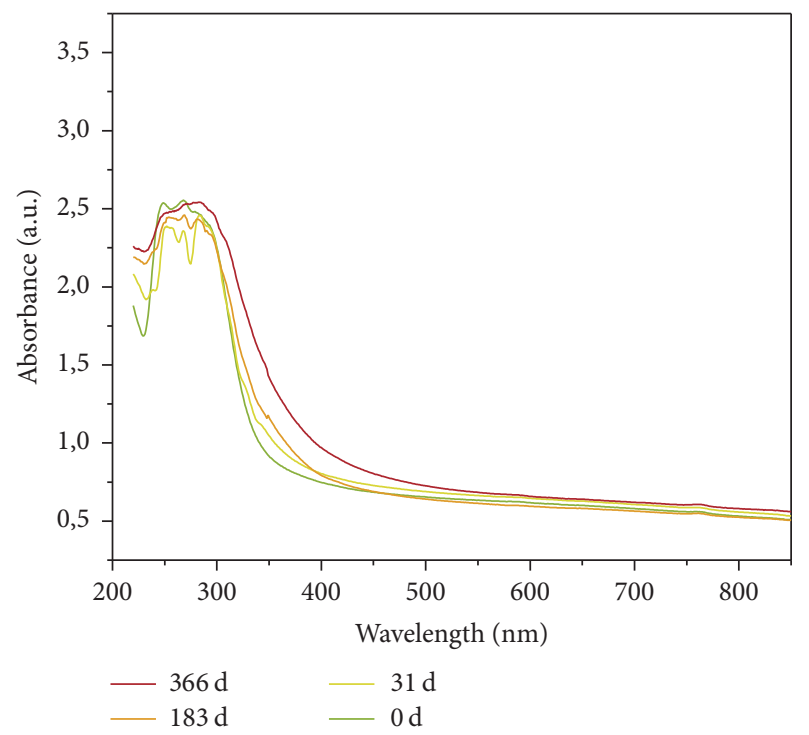

FIGURE 3: UV-Vis absorption spectra of UHMW-PE after pure thermal aging at $125^{\circ} \mathrm{C}$.

enable, for example, radical recombination or postirradiation oxidation [15] as discussed above.

In the untreated material, the radicals that were formed by chain scission reactions in the crystalline regions of the polymer during irradiation were trapped there (as reported also in $[13,20]$ ) until a melting of the crystals occurred during the first heating run of DSC experiments. As the broken chains are shorter and thus more mobile, the polymer chains could arrange themselves into crystals more easily during subsequent cooling, which can be observed as a higher degree of crystallinity of the irradiated samples in

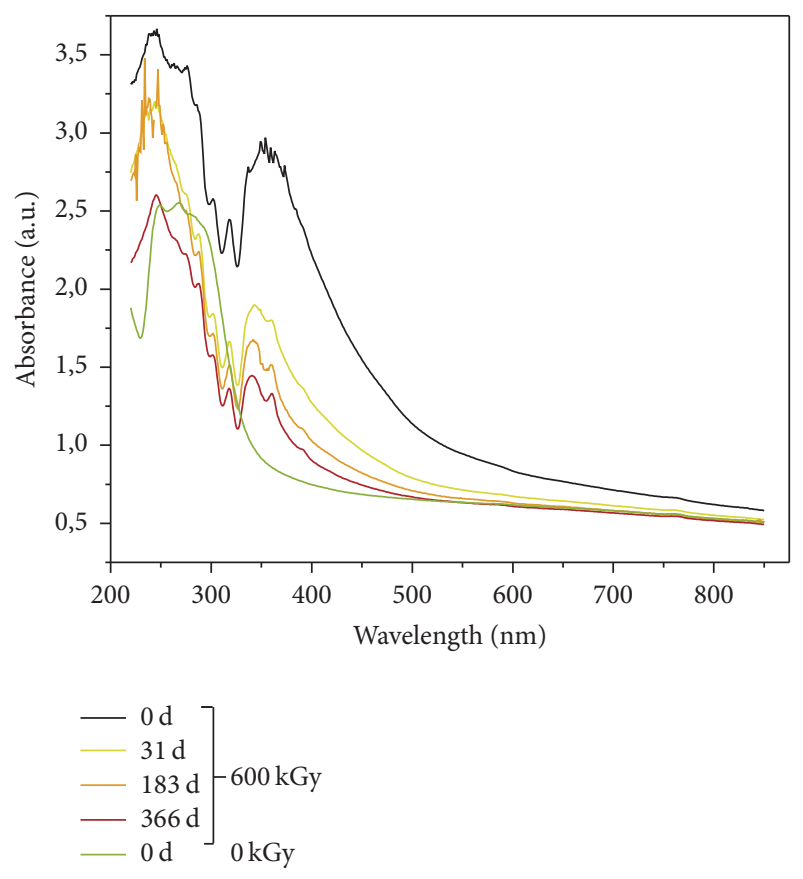

FIGURE 4: UV-Vis absorption spectra of UHMW-PE after irradiation with $600 \mathrm{kGy}$ and subsequent thermal aging at $125^{\circ} \mathrm{C}$. The spectrum for untreated material is given as well.

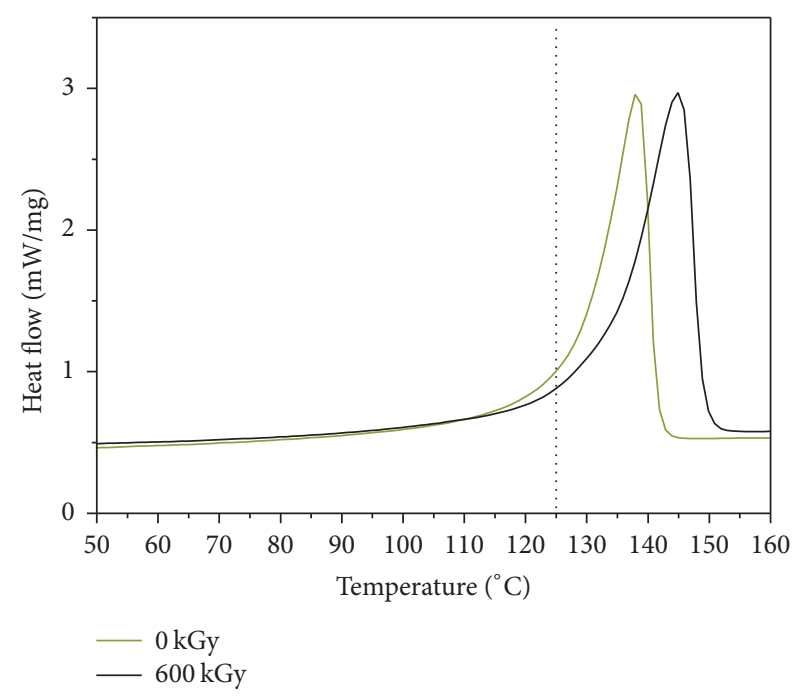

FIGURE 5: DSC curves of untreated and irradiated (600 kGy) UHMW-PE material. The temperature for subsequent thermal aging $\left(125^{\circ} \mathrm{C}\right)$ is marked by the dotted line.

the second heating run (Figure 6). As can also be seen in Figure 6, subsequent thermal aging resulted in a decrease of crystallinity back to the initial level, which is most likely due to radical recombination at the higher aging temperature that led again to longer and thus less mobile chains. This observation is in agreement with the results reported so far in literature $[25,26]$. 


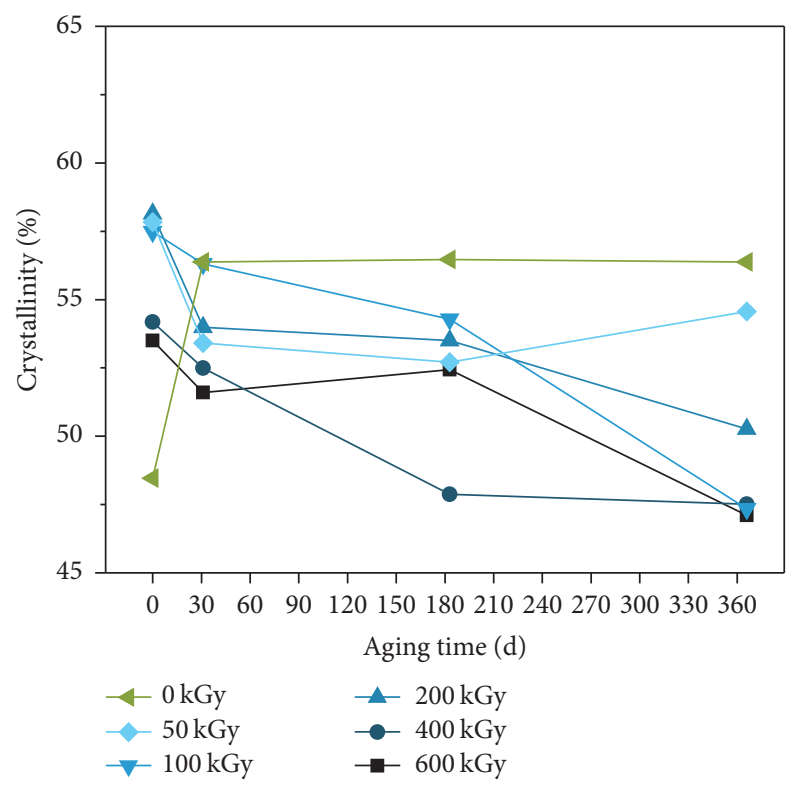

FIGURE 6: Crystallinity of UHMW-PE determined from the second heating of DSC measurements.

3.1.4. FTIR Spectroscopy. For further identification of the chemical species that formed during the treatment of the material, FTIR spectroscopy was performed and results are shown in Figure $7(\mathrm{a})\left(1800-1525 \mathrm{~cm}^{-1}\right)$ and Figure $7(\mathrm{~b})$ $\left(1200-800 \mathrm{~cm}^{-1}\right)$, respectively. Firstly, the formation of carboxylic species, which absorb in the range of $1700-1800 \mathrm{~cm}^{-1}$ [27], is observed in FTIR spectra after irradiation (Figure $7(a)$ ). Although the peak signal exceeds the acceptable absorbance value of about 3 according to Lambert-Beer law, the broad base of the signal in this area clearly indicates an oxidation process. For untreated material, no significant changes can be observed. The gradual increase of this peak with radiation dose could be observed in the spectra of purely irradiated samples published previously in [5]. When additional thermal aging is applied for the irradiated sample, the peak gradually decreases almost back to the baseline level. This suggests that carbonylic species are at least partly responsible for the discoloration after irradiation and its reversal after additional thermal aging that was also obvious in UV-Vis spectra. The decrease of the carbonyl peak can possibly be attributed to chain scission at the ketone group, conversion to carboxyl group by further oxidation, and subsequent elimination of $\mathrm{CO}$ or $\mathrm{CO}_{2}$ from terminal carbonyl groups. Furthermore, a peak at $965 \mathrm{~cm}^{-1}$ formed as a result of irradiation [28]. This peak corresponds to the $\mathrm{sp}^{2} \mathrm{C}-\mathrm{H}$ bend of trans-vinylene double bonds [29] that probably formed due to abstraction of $\mathrm{H}$ radicals and subsequent double bond formation [11]. Pure thermal aging led to an increase of this peak. When the sample is irradiated, a compatible increase is observable; however, it can be seen that this peak decreases when subsequent thermal aging is applied, possibly because of oxidation of the reactive double bonds. Remarkably, compared to the carbonyl bands, the intensity of this band keeps constant and independent from the aging time. This indicates a saturation effect.

3.2. HMW-PE. The second investigated material was a HMW-PE that contained a phenolic antioxidant. High discoloration was observed after gamma irradiation and thermal aging. In contrast to the UHMW-PE samples, black spots appeared in the polymer during thermal aging (Figure 8), growing in size and number with thermal aging time.

3.2.1. Colorimetry. The changes in color were quantified through the yellowness index (YI) after $L^{*} a^{*} b^{*}$ colorimetry measurements on each sample (Figure 9). While untreated UHMW-PE exhibited a YI of about -30, the YI of untreated HMW-PE yielded a value of -10 . A possible reason could be that the antioxidant in HMW-PE slightly alters the material color. In contrast to the UHMW-PE, where thermal aging caused almost no discoloration, both irradiation and thermal aging caused yellowing of the HMW-PE. Two effects apparently contribute to discoloration. One is the discoloration by irradiation that reaches a maximum around a YI of 55 and, as for UHMW-PE, decreases when thermal aging is applied after gamma irradiation. The second effect is the continuous increase of yellowness by thermal aging. As HMW-PE exhibits an additional mechanism that causes permanent discoloration, higher yellowness levels compared to UHMW-PE were reached.

The reversible discoloration after irradiation can be attributed to the same mechanism as in the case of UHMW$\mathrm{PE}$, namely, the formation of macroradicals that recombine upon aging at higher temperature. As the polymer chains of HMW-PE are shorter compared to UHMW-PE, this happens much faster. Another explanation for the reversible discoloration could be the migration and evaporation of discoloring substances [30] (e.g., evaporation of low molecular weight substances resulting from the decomposition of the antioxidant). The discoloration caused by thermal aging in the antioxidant-containing HMW-PE can most likely be attributed to decomposition products of the stabilizer. For instance, when phenolic stabilizers decompose (either by radical transfer reactions with a polymer macroradical or by oxidation), they may form byproducts such as quinoidal compounds that greatly discolor the material [31].

3.2.2. UV-Vis Spectroscopy. The UV-Vis spectra of the HMW$\mathrm{PE}$ samples provide additional information. Pure irradiation (Figure 10) led to a general increase of absorbance and a broader peak around $350-400 \mathrm{~nm}$, the same wavelength region as the one where the peak formed after irradiation of UHMW-PE (cf. Figure 2). In the case of the untreated HMW$\mathrm{PE}$, a peak is observed at $282 \mathrm{~nm}$, which can be attributed to a sterically hindered phenolic stabilizer [32]. This absorption peak is probably responsible for the higher yellowness index of the untreated HMW-PE in comparison to UHMW-PE. This peak decreases with thermal aging time (Figure 11), while a new peak at $400 \mathrm{~nm}$ is formed simultaneously that is most likely related to decomposition products of the antioxidant, for example, the highly color-altering substituted quinone methides which absorb light in the range of 420-465 $\mathrm{nm}$ [31]. 


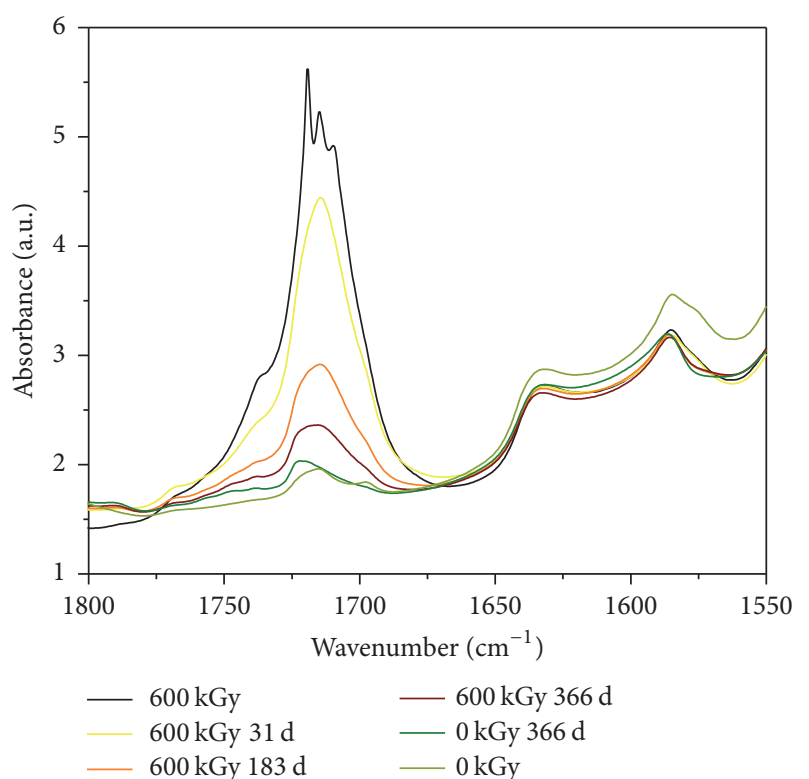

(a)

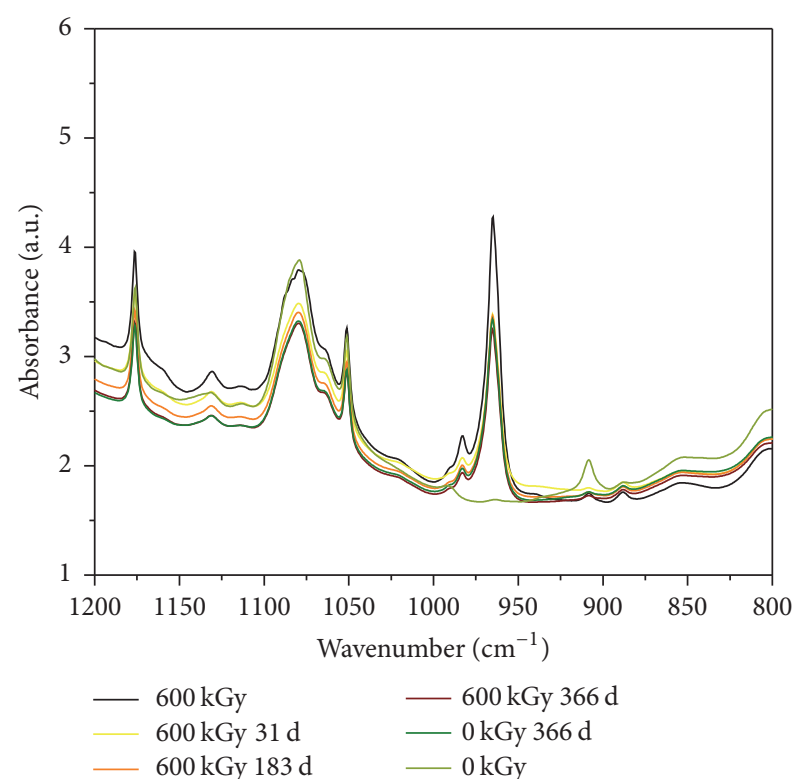

(b)

FIGURE 7: FTIR spectra of UHMW-PE for different aging states.

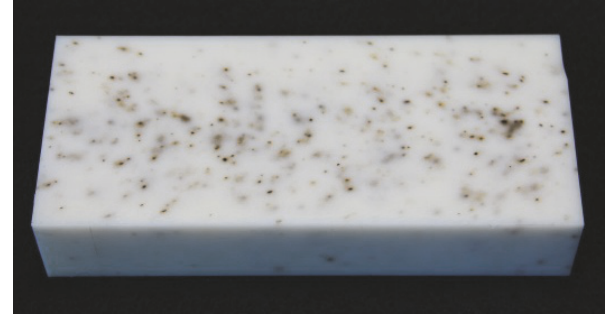

Figure 8: A block $(200 \mathrm{~mm} \times 80 \mathrm{~mm} \times 40 \mathrm{~mm})$ of HMW-PE with black spots that appeared after 31 days of pure thermal aging at $125^{\circ} \mathrm{C}$.

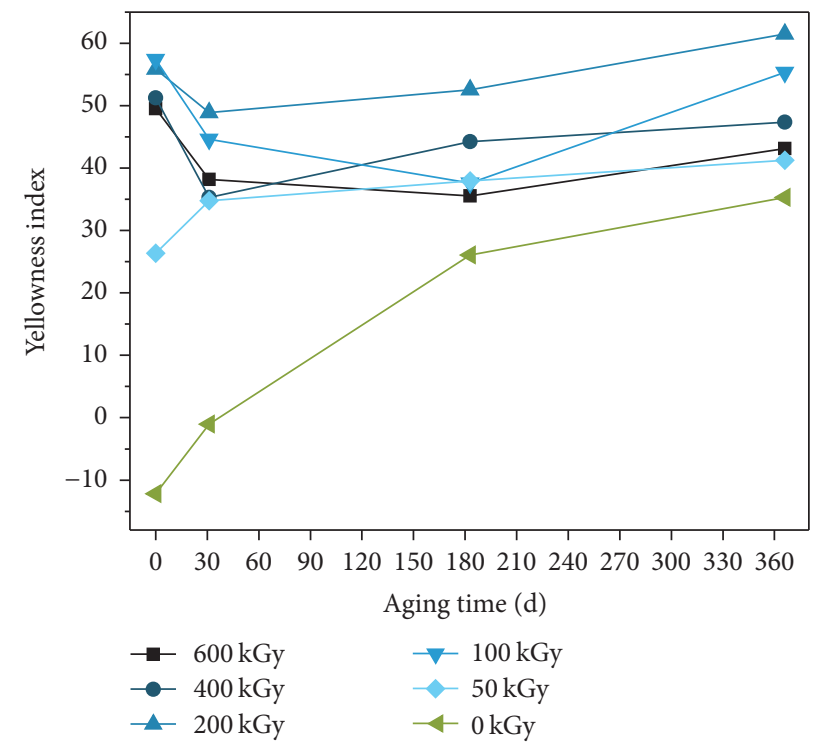

FIgURE 9: Yellowness index of HMW-PE after irradiation and subsequent thermal aging at $125^{\circ} \mathrm{C}$.

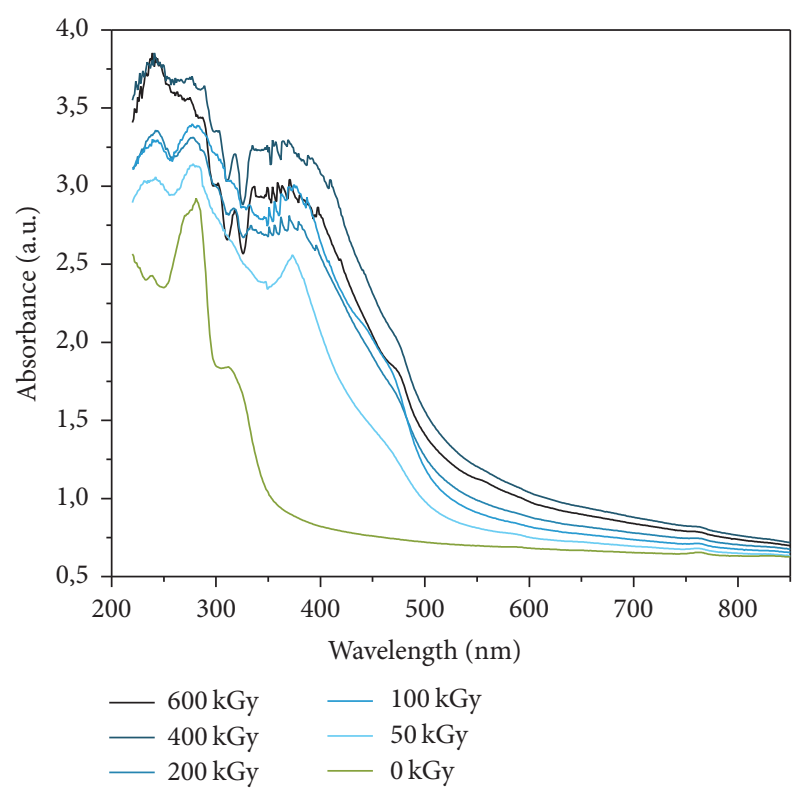

FIGURE 10: UV-Vis absorption spectra of HMW-PE after irradiation with different doses.

(The exact wavelength at which the maximum absorbance occurs depends on the exact chemical structure of the quinoidal compound [32].) When the irradiated samples were thermally aged (Figure 12), the broad peak around $400 \mathrm{~nm}$ decreases presumably because of recombination of radicals that form the annealable color centers until only the permanent contribution from decomposed antioxidant remains. The fact that the remaining peak height differs from 


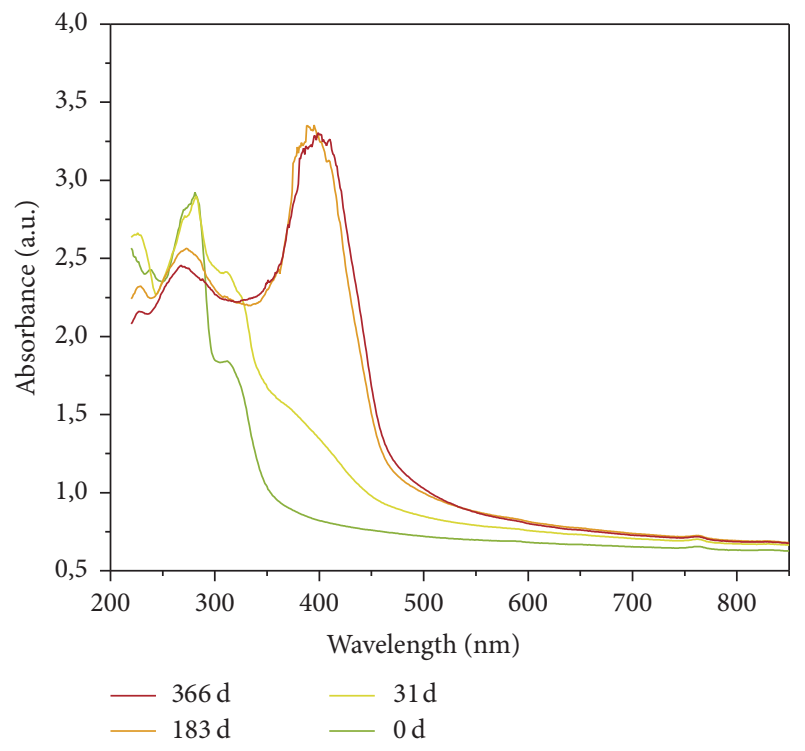

Figure 11: UV-Vis absorption spectra of HMW-PE after pure thermal aging at $125^{\circ} \mathrm{C}$.

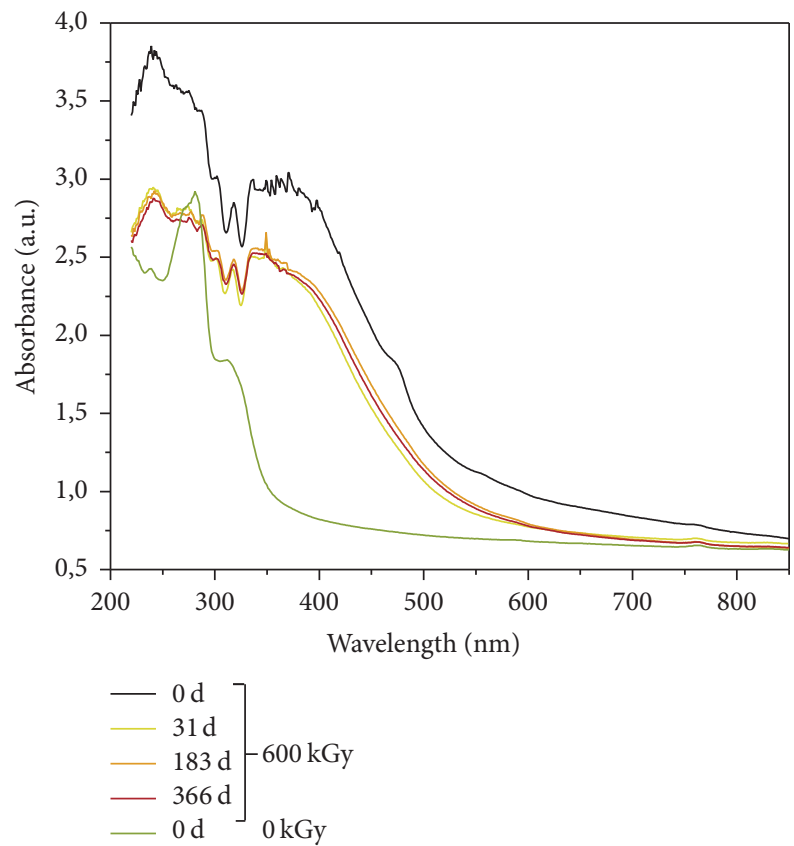

FIGURE 12: UV-Vis absorption spectra of HMW-PE after irradiation with $600 \mathrm{kGy}$ and subsequent thermal aging at $125^{\circ} \mathrm{C}$. The spectrum for untreated material is given as well.

pure thermal aging might be due to chemical changes of the antioxidant resulting from the irradiation.

3.2.3. DSC. Figure 13 shows the DSC curves of the first heating run, which corresponds to the material behavior before the application of thermal loads, both before and after irradiation. As for UHMW-PE, at $125^{\circ} \mathrm{C}$ (the temperature at which thermal aging is applied afterwards), the melting process has already started, meaning that molecular

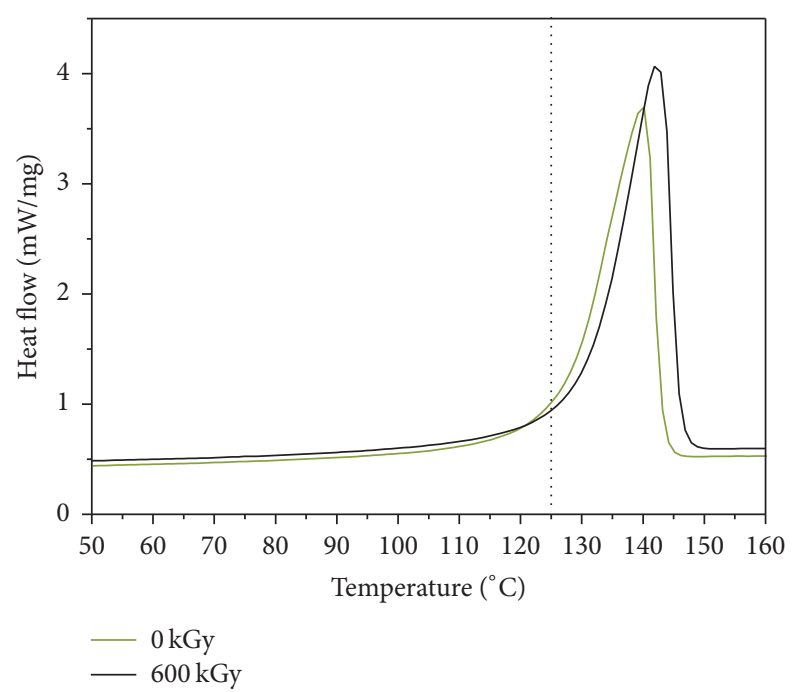

FIGURE 13: DSC curves of untreated and irradiated (600 kGy) HMW-PE material. The temperature for subsequent thermal aging $\left(125^{\circ} \mathrm{C}\right)$ is marked by the dotted line.

rearrangements and radical migration are possible at this temperature. Additionally, the melting peak has grown and shifted to higher temperatures after irradiation.

Figure 14 shows the degree of crystallinity of HMW-PE calculated from the second heating run of DSC experiments. Firstly, untreated HMW-PE exhibits a higher degree of crystallinity than untreated UHMW-PE (Figure 6), probably because the chains of HMW-PE are shorter and thus more mobile than those of UHMW-PE. In contrast to UHMW$\mathrm{PE}$, the crystallinity changes in dependence of irradiation dose: a decrease can be observed. During thermal aging (except for the most strongly irradiated and thermally aged sample), no change of the crystallinity level can be observed, possibly because the antioxidant prevents oxidation of the chains (which would hinder crystallization) during thermal aging. A possible reason for that can be the cross-linking of chains which lowers mobility and the ability to form crystal layers during cooling after the first heating run, thus leading to reduced crystallinity in the second heating run.

3.2.4. FTIR Spectroscopy. FTIR spectroscopy results are shown in Figure 15(a) $\left(1800-1525 \mathrm{~cm}^{-1}\right)$ and Figure 15(b) (1200-800 $\left.\mathrm{cm}^{-1}\right)$, respectively. The principle FTIR spectra of HMW-PE are similar to the ones of UHMW-PE (Figure 7). However, significant differences are the intense absorption peak at $908 \mathrm{~cm}^{-1}$ and at $1640 \mathrm{~cm}^{-1}$ of the untreated HMWPE. These peaks are attributed to vinyl chain ends [27] and are probably a result of either chain transfer that occasionally takes place during Ziegler-Natta polymerization [11] or is an indication that the polymer was produced with Phillips-type catalyst containing chromium oxide [33]. Such unsaturations are very reactive [11] and will react quickly with radicals formed by irradiation, which explains why the peak almost disappears after irradiation. When only thermal aging is applied, the peak decreases more slowly. We conclude that 


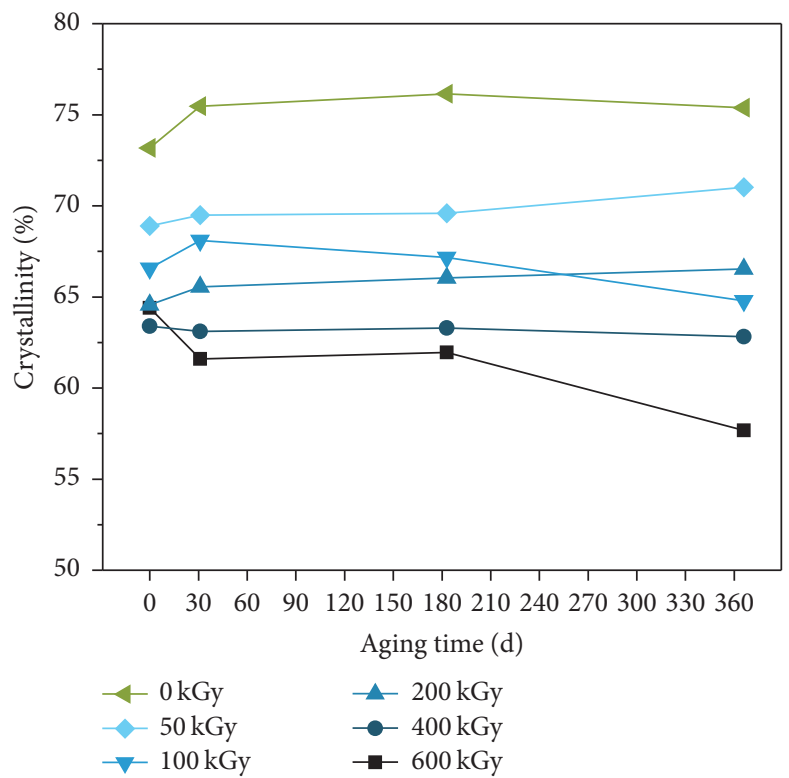

FIGURE 14: Crystallinity of HMW-PE determined from the second heating run of DSC measurements.

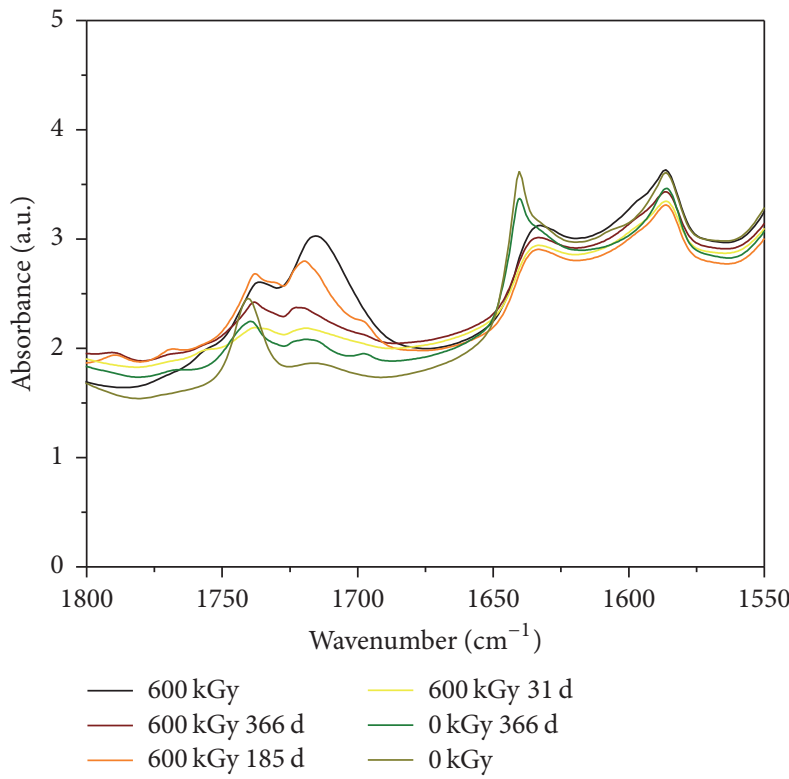

(a)

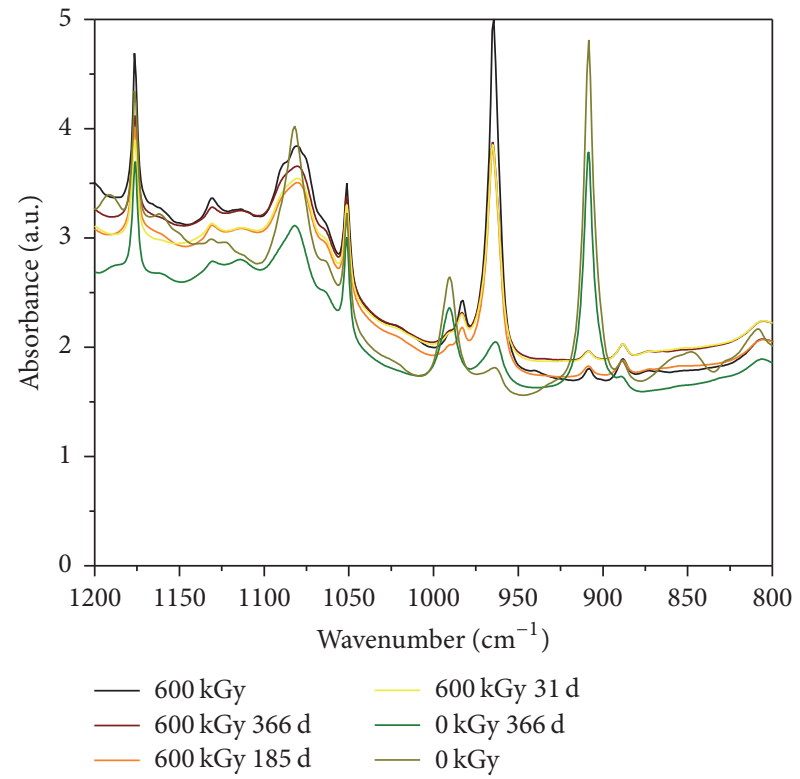

(b)

FIGURE 15: FTIR spectra of HMW-PE for different aging states.

these double bonds react favorably with carbon radicals during irradiation, and the presence of oxygen radicals during aging is less critical.

Similar to UHMW-PE, irradiation with $600 \mathrm{kGy}$ resulted in the formation of unsaturations in the form of transvinylene bonds in the polymer chain $\left(965 \mathrm{~cm}^{-1}\right.$, Figure $\left.15(\mathrm{~b})\right)$ that decreased after subsequent thermal aging (probably because of oxidation). The formation of carbonyl groups (1750-1700 $\mathrm{cm}^{-1}$, Figure 15(a)) behaves very different compared to UHMW-PE. It should be noticed that this area is also affected by additional signal of the antioxidant $\left(\sim 1735 \mathrm{~cm}^{-1}\right)$.
Similar to UHMW-PE, the aging of the untreated material does not influence the signal significantly. However, in contrast to UHMW-PE, the irradiation does not increase the peak significantly; consequently the former observed decrease of the carbonyl signal with aging time could not be observed. We conclude that the activity of the antioxidant suppresses the oxidation process.

Similar to UHMW-PE, only a very small carbonyl peak could be observed after one year of thermal aging in the stabilized HMW-PE. However, it is possible that oxidation is concentrated in the black spots that were formed in the 
material (see Figure 8) and that could not be examined by color, UV-Vis, and FTIR measurements. The black spots are probably formed when catalyst residues from polymer synthesis, like titanium chloride (e.g., $\mathrm{TiCl}_{3}$ ) and chromium (Cr) particles, react with the phenolic antioxidant to produce chromophoric species, such as titanium phenolates [34-37]. As these catalyst residues promote hydroperoxide decomposition [38], oxidation preferentially starts at the polymercatalyst interface.

3.3. Relevance of Degradation Effects for the Neutron Shielding Properties. The hydrogen content of the materials is the determining parameter for the neutron radiation shielding. Degradation by gamma irradiation or thermal loads can lead to the scission of $\mathrm{C}-\mathrm{H}$ bonds, resulting in the release of hydrogen that is no longer of use for the neutron radiation shielding purpose. Evidence that hydrogen is lost is found in IR spectra of both materials in the form of trans-vinylene double bonds (indicating scission of neighboring C-H bonds) and oxidation species (in which oxygen replaces one or two hydrogen atoms). As UHMW-PE contains no antioxidant, a more pronounced oxidation is observed, suggesting a higher hydrogen loss. However, the examined material properties exhibit significant degradation only after applying very high radiation doses. Taking into account the decay behavior of the radioactive content and the limited oxygen availability in the cask assembly, a significant impairment of the shielding capability during service is not expected.

\section{Conclusions}

The influence of irradiation and subsequent thermal aging on (U)HMW-PE was studied by colorimetry, UV-Vis, DSC, and FTIR. By irradiation, a clear color change was induced which could partly be neutralized by thermal annealing. The thermal treatment of unirradiated material leads also to an increase in YI which was used to interpret the color changes with aging time. The observed main findings are given in the following for the two materials.

In the case of UHMW-PE, the change in color and UVVis spectra is apparently mostly due to the formation of annealable color centers in the form of trapped radicals that recombine at the higher aging temperature, leading to a reversal of the discoloration and the decrease of the degree of crystallinity back to the initial value. IR spectra also showed clear effects after irradiation that were partly reversible after subsequent thermal treatment.

By contrast, the bulk color change of HMW-PE was mostly permanent. Thus, the major color change was attributed to decomposition products of a phenolic antioxidant. Additionally, black spots appeared after thermal aging, growing in size and number with time, which are assumed to be a result of reactions between antioxidant decomposition products and catalyst residues from polymer synthesis, both of which are not present in the UHMW-PE.

Regarding the neutron shielding properties which depend on the hydrogen content, IR spectra show evidence that hydrogen is eliminated or replaced by oxygen, especially in UHMW-PE and after applying high radiation doses.
However, taking into account the decay behavior of the radioactive content and the limited availability of oxygen in the cask assembly, no significant impairment of the shielding capability is expected during service.

\section{Conflicts of Interest}

The authors declare that there are no conflicts of interest regarding the publication of this paper.

\section{Acknowledgments}

Parts of the presented project were funded by the German Federal Ministry of Economic Affairs and Energy (BMWi, Project no. 1501509) on the basis of a decision by the German Bundestag.

\section{References}

[1] S. M. Kurtz, The UHMWPE Handbook: Ultra-High Molecular Weight Polyethylene in Total Joint Replacement, Elsevier Science, 2004.

[2] J. Shapiro, Radiation Protection: A Guide for Scientists, Regulators, and Physicians, Harvard University Press, 2002.

[3] D. Wolff, K. von der Ehe, M. Jaunich et al., "(U)HMWPE as Neutron Radiation Shielding Materials: Impact of Gamma Radiation on Structure and Properties," in Effects of Radiation on Nuclear Materials, vol. 25, ASTM International, 2013.

[4] K. von der Ehe, A. Kömmling, and D. Wolff, "Neutron radiation shielding material polyethylene: consequences of gamma irradiation," in Waste Management Symposia, WM Symposia, Phoenix, Arizona, USA, 2015.

[5] A. Kömmling, K. von der Ehe, D. Wolff, and M. Jaunich, "Effect of high-dose gamma irradiation on (U)HMWPE neutron shielding materials," Radiation Physics and Chemistry, 2016.

[6] H. Hinsken, S. Moss, J.-R. Pauquet, and H. Zweifel, "Degradation of polyolefins during melt processing," Polymer Degradation and Stability, vol. 34, no. 1-3, pp. 279-293, 1991.

[7] L. Costa, I. Carpentieri, and P. Bracco, "Post electron-beam irradiation oxidation of orthopaedic UHMWPE," Polymer Degradation and Stability, vol. 93, no. 9, pp. 1695-1703, 2008.

[8] P. Bracco, V. Brunella, M. P. Luda, E. M. Brach del Prever, M. Zanetti, and L. Costa, "Oxidation behaviour in prosthetic UHMWPE components sterilised with high-energy radiation in the presence of oxygen," Polymer Degradation and Stability, vol. 91, no. 12, pp. 3057-3064, 2006.

[9] P. Bracco, E. M. Brach del Prever, M. Cannas, M. P. Luda, and L. Costa, "Oxidation behaviour in prosthetic UHMWPE components sterilised with high energy radiation in a lowoxygen environment," Polymer Degradation and Stability, vol. 91, no. 9, pp. 2030-2038, 2006.

[10] C. F. Coote, J. V. Hamilton, W. G. McGimpsey, and R. W. Thompson, "Oxidation of gamma-irradiated ultrahigh molecular weight polyethylene," Journal of Applied Polymer Science, vol. 77, no. 11, pp. 2525-2542, 2000.

[11] V. Premnath, W. H. Harris, M. Jasty, and E. W. Merrill, "Gamma sterilization of UHMWPE articular implants: an analysis of the oxidation problem," Biomaterials, vol. 17, no. 18, pp. 1741-1753, 1996.

[12] J. S. Wallace, M. B. Sinclair, K. T. Gillen, and R. L. Clough, "Color center annealing in $\gamma$ - irradiated polystyrene, under vacuum 
and air atmospheres," Radiation Physics and Chemistry, vol. 41, no. 1-2, pp. 85-100, 1993.

[13] M. J. Martínez-Morlanes, A. Terriza, F. Yubero, and J. A. Puértolas, "Characterization of highly crosslinked polyethylenes by colorimetry," Polymer Testing, vol. 31, no. 6, pp. 841847, 2012.

[14] R. Biswas, H. Sahadath, A. S. Mollah, and M. F. Huq, "Calculation of gamma-ray attenuation parameters for locally developed shielding material: Polyboron," Journal of Radiation Research and Applied Sciences, vol. 9, no. 1, pp. 26-34, 2016.

[15] I. Carpentieri, V. Brunella, P. Bracco et al., "Post-irradiation oxidation of different polyethylenes," Polymer Degradation and Stability, vol. 96, no. 4, pp. 624-629, 2011.

[16] J. Schanda, Colorimetry: Understanding the CIE System, Wiley, 2007.

[17] K. Del Teso Sánchez, N. S. Allen, C. M. Liauw et al., "Effects of polymerization catalyst technology on the melt processing stability of polyethylenes. part 2. single stabilizer performance," Journal of Vinyl and Additive Technology, vol. 18, no. 1, pp. 26-39, 2012.

[18] U. Schade, A. Röseler, E. H. Korte et al., "New infrared spectroscopic beamline at BESSY II," Review of Scientific Instruments, vol. 73, no. 3, pp. 1568-1570, 2002.

[19] G. W. Ehrenstein, G. Riedel, and P. Trawiel, Praxis der Thermischen Analyse von Kunststoffen, Hanser, 2003.

[20] R. L. Clough, K. T. Gillen, G. M. Malone, and J. S. Wallace, "Color formation in irradiated polymers," Radiation Physics and Chemistry, vol. 48, no. 5, pp. 583-594, 1996.

[21] R. L. Clough, G. M. Malone, K. T. Gillen, J. S. Wallace, and M. B. Sinclair, "Discoloration and subsequent recovery of optical polymers exposed to ionizing radiation," Polymer Degradation and Stability, vol. 49, no. 2, pp. 305-313, 1995.

[22] L. M. Gorghiu, S. Jipa, T. Zaharescu, R. Setnescu, and I. Mihalcea, "The effect of metals on thermal degradation of polyethylenes," Polymer Degradation and Stability, vol. 84, no. 1, pp. 7-11, 2004.

[23] E. A. B. Moura, A. V. Ortiz, H. Wiebeck, A. B. A. Paula, A. L. A. Silva, and L. G. A. Silva, "Effects of gamma radiation on commercial food packaging films - Study of changes in UV/VIS spectra," Radiation Physics and Chemistry, vol. 71, no. 1-2, pp. 201-204, 2004.

[24] D. M. Bodily and M. Dole, "Ultraviolet spectroscopy of irradiated polyethylene," The Journal of Chemical Physics, vol. 45, no. 5, pp. 1428-1432, 1966.

[25] I. Kamel and L. Finegold, "Effect of radiation on the structure of ultrahigh molecular weight polyethylene," Radiation Physics and Chemistry, vol. 26, no. 6, pp. 685-691, 1985.

[26] S. K. Bhateja, E. H. Andrews, and R. J. Young, "Radiationinduced crystallinity changes in linear polyethylene," Journal of Polymer Science: Polymer Physics Edition, vol. 21, no. 4, pp. 523536, 1983.

[27] J. P. Luongo, "Infrared study of oxygenated groups formed in polyethylene during oxidation," Journal of Polymer Science, vol. 42, no. 139, pp. 139-150, 1960.

[28] J. Beckmann, U. Schade, K. von der Ehe, M. Jaunich, D. Wolff, and E. F. Aziz, "THz and Mid IR fourier transform spectroscopy on polyethylene irradiated with $\gamma$-Co60 radiation," in Proceedings of the 39th International Conference on Infrared, Millimeter and Terahertz Waves, IRMMW-THz 2014, September 2014.

[29] G. N. Patel, "Crystallinity and the effect of ionizing radiation in polyethylene. V. Distribution of trans-vinylene and trans, trans conjugated double bonds in linear polyethylene," Journal of Polymer Science: Polymer Physics Edition, vol. 13, no. 2, pp. 351359, 1975.

[30] K. Grabmayer, G. M. Wallner, S. Beißmann et al., "Accelerated aging of polyethylene materials at high oxygen pressure characterized by photoluminescence spectroscopy and established aging characterization methods," Polymer Degradation and Stability, vol. 109, pp. 40-49, 2014.

[31] J. Pospíšil, W.-D. Habicher, J. Pilař et al., "Discoloration of polymers by phenolic antioxidants," Polymer Degradation and Stability, vol. 77, no. 3, pp. 531-538, 2002.

[32] P. P. Klemchuk and P.-L. Horng, "Transformation products of hindered phenolic antioxidants and colour development in polyolefins," Polymer Degradation and Stability, vol. 34, no. 1-3, pp. 333-346, 1991.

[33] E. Epacher, C. Kröhnke, and B. Pukánszky, "Effect of catalyst residues on the chain structure and properties of a Phillips type polyethylene," Polymer Engineering and Science, vol. 40, no. 6, pp. 1458-1468, 2000.

[34] J. Kresta and J. Majer, "Effect of titanium compounds on thermooxidative properties of stabilized polypropylene," Journal of Applied Polymer Science, vol. 13, no. 9, pp. 1859-1871, 1969.

[35] E. Epacher, J. Tolvéth, C. Kröhnke, and B. Pukánszky, "Processing stability of high density polyethylene: effect of adsorbed and dissolved oxygen," Polymer, vol. 41, no. 23, pp. 8401-8408, 2000.

[36] N. S. Allen, C. M. Liauw, A. Reyes, M. Edge, B. Johnson, and K. Keck-Antoine, "Color inhibition of phenolic antioxidants in Ziegler-Natta polyethylene. I. In-situ polymer studies," Journal of Vinyl and Additive Technology, vol. 15, no. 1, pp. 12-19, 2009.

[37] N. A. Mukmeneva, Polyfunctional Stabilizers of Polymers, Nova Science Publishers, 2009.

[38] G. N. Foster, S. H. Wasserman, and D. J. Yacka, "Oxidation behavior and stabilization of metallocene and other polyolefins," Angewandte Makromolekulare Chemie, vol. 252, pp. 1132, 1997. 

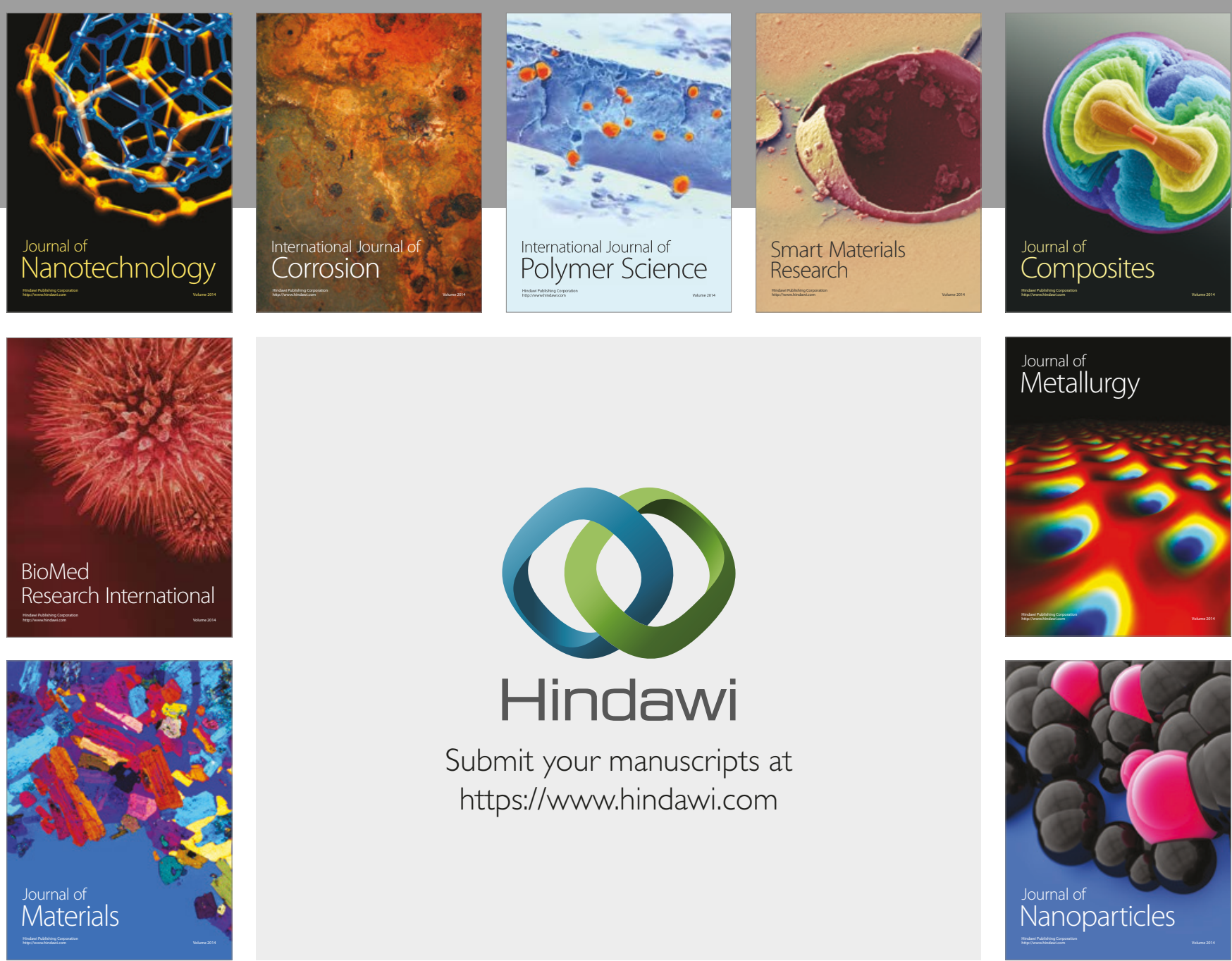

\section{Hindawi}

Submit your manuscripts at

https://www.hindawi.com
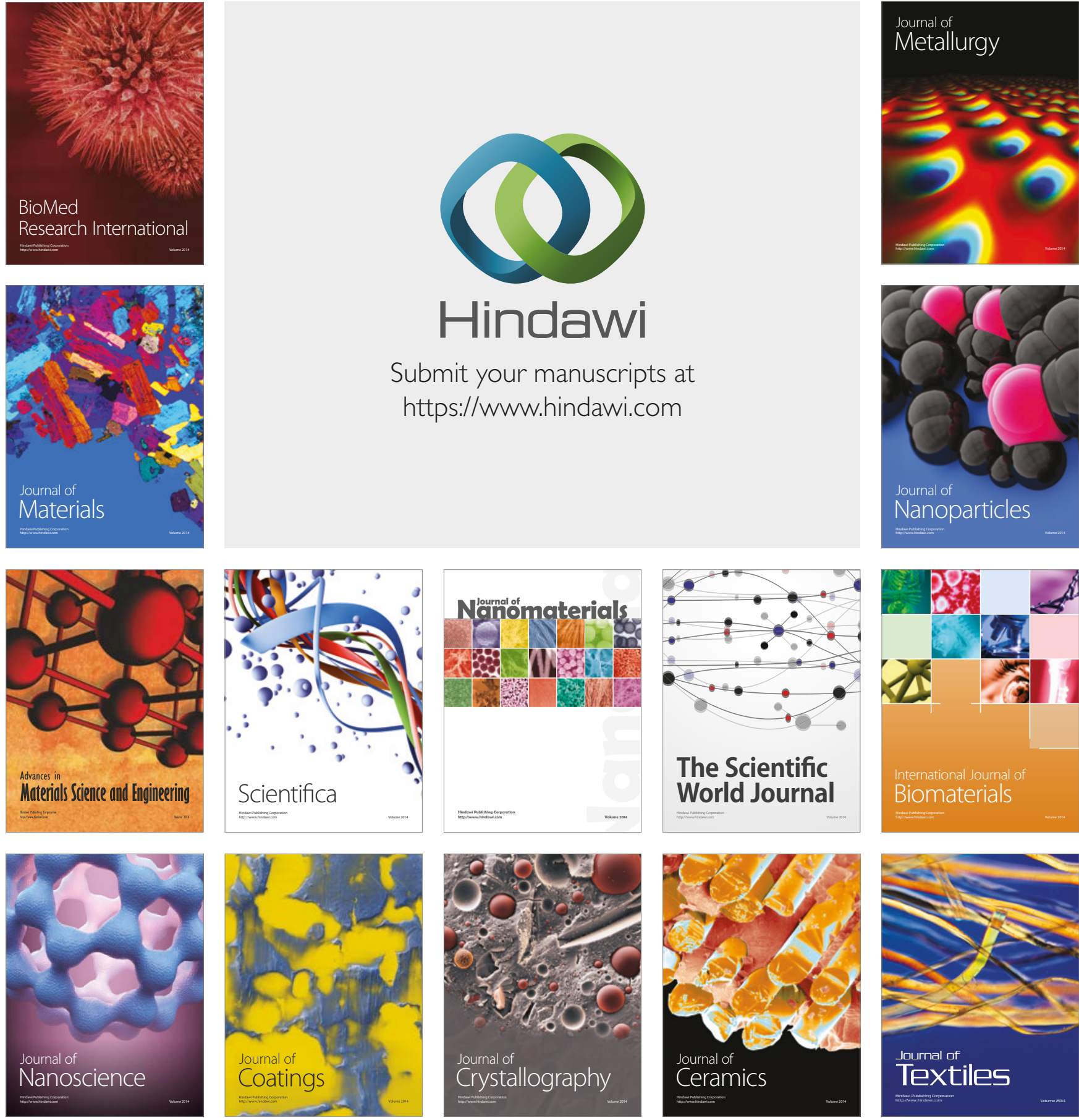

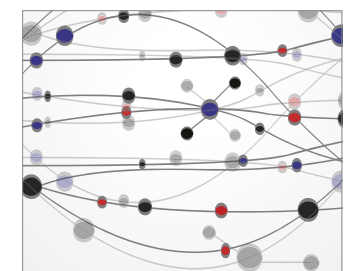

The Scientific World Journal
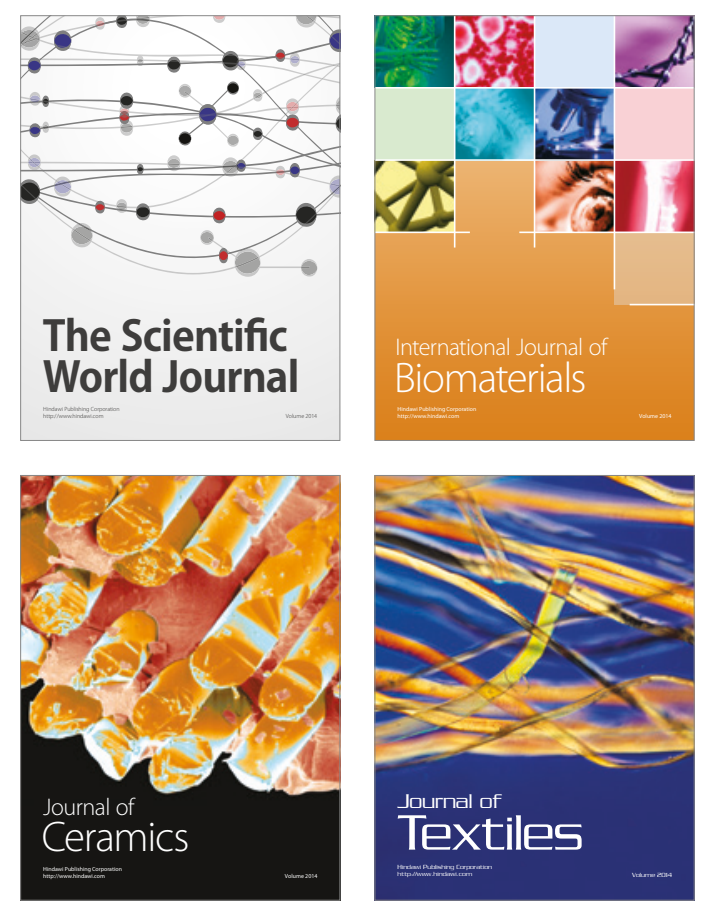